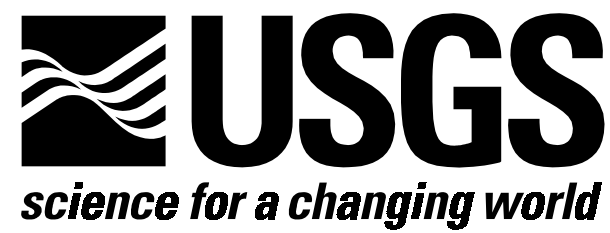

\title{
A New Method for GPS-
} based Wind Speed

Determinations during

Airborne Volcanic Plume Measurements

By Michael P. Doukas ${ }^{1}$

Open-File Report 02-395

2002

This report is preliminary and has not been reviewed for conformity with U.S. Geological Survey editorial standards or with the North American Stratigraphic Code. Any use of trade, product, or firm names is for descriptive purposes only and does not imply endorsement by the U.S.

Government.

U.S. GEOLOGICAL SURVEY

U.S. DEPARTMENT OF THE INTERIOR

${ }^{1}$ David A. Johnston Cascades Volcano Observatory 


\section{Introduction}

Begun nearly thirty years ago, the measurement of gases in volcanic plumes is today an accepted technique in volcano research. Volcanic plume measurements, whether baseline gas emissions from quiescent volcanoes or more substantial emissions from volcanoes undergoing unrest, provide important information on the amount of gaseous output of a volcano to the atmosphere. Measuring changes in gas emission rates also allows insight into eruptive behavior. Some of the earliest volcanic plume measurements of sulfur dioxide were made using a correlation spectrometer (COSPEC). The COSPEC, developed originally for industrial pollution studies, is an upward-looking optical spectrometer tuned to the ultraviolet absorption wavelength of sulfur dioxide (Millán and Hoff, 1978). In airborne mode, the COSPEC is mounted in a fixed-wing aircraft and flown back and forth just underneath a volcanic plume, perpendicular to the direction of plume travel (Casadevall and others, 1981; Stoiber and others, 1983). Similarly, for plumes close to the ground, the COSPEC can be mounted in an automobile and driven underneath a plume if a suitable road system is available (Elias and others, 1998). The COSPEC can also be mounted on a tripod and used to scan a volcanic plume from a fixed location on the ground, although the effectiveness of this configuration declines with distance from the plume (Kyle and others, 1990). In the 1990's, newer airborne techniques involving direct sampling of volcanic plumes with infrared spectrometers and electrochemical sensors were developed in order to measure additional gases such as $\mathrm{CO}_{2}$ and $\mathrm{H}_{2} \mathrm{~S}$ (Gerlach and others, 1997; Gerlach and others, 1999; McGee and others, 2001). These methods involve constructing a plume cross-section from several measurement traverses through the plume in a vertical plane. Newer instruments such as open-path Fourier transform infrared (FTIR) spectrometers are now being used to measure the gases in volcanic plumes mostly from fixed locations on the ground. Most FTIR studies to date measure only gas compositions or ratios of gas species (Love and others, 1998; Francis and others, 1998; Horrocks and others, 1999). What all of these methods have in common, however, is the necessity to know plume velocities if accurate gas emission rates are to be calculated. Even open-path FTIR studies done in tandem with a COSPEC require knowledge of plume velocity in order to compute emission rates.

When gases exit a volcanic vent, they typically rise until they achieve their level of buoyancy in the atmosphere (McGee, 1992). Quiescent volcanoes with boiling temperature fumaroles typically produce low energy plumes in the atmosphere at about the same elevation as the fumaroles that discharge the gases. At volcanoes where the gases are discharged under high pressure and temperature, plumes will rise to greater elevations while undergoing adiabatic expansion and cooling. Ultimately they too will reach an altitude where they are in thermal equilibrium with the atmosphere and where wind shear stresses overcome their initial momentum and buoyancy (McGee, 1992). Although meteorological conditions will affect plumes in various ways upon exit from a volcanic vent, once a plume bends over and becomes horizontal, it will begin to travel downwind at the speed of the ambient wind. Plume velocity then can be assumed to be the same as the wind speed and the gases in the plume can then be 
measured using any of the methods described above and, along with the wind speed, be used to compute an emission rate.

Equation (1), adapted from Gerlach and others (1997) is the generalized formula for calculating a gas emission rate $(E)$ using multiple plume traverses to produce a plume crosssection:

$$
E=k\left(A S P_{\text {gas }}\right) T^{-1}
$$

where $A$ is the area of plume cross-section $\left(\mathrm{m}^{2}\right), S$ is the average plume velocity $\left(\mathrm{ms}^{-1}\right), P_{\text {gas }}$ is the partial pressure of the gas $(\mathrm{Pa})$ in the plume calculated from the product of average barometric pressure and the average molar concentration of the gas in the plume, and $T$ is the average air temperature in the plume $(\mathrm{K})$. The constant $\mathrm{k}$ includes the formula weight of the gas, the universal gas constant, and the number of seconds in a day. The average gas concentration in the plume cross-section is determined using kriging models for griding and contouring the concentration measurements. $E$ is generally expressed in units of metric tonnes $\left(10^{3} \mathrm{~kg}\right)$ per day $\left(\mathrm{td}^{-1}\right)$. The method for calculating $\mathrm{SO}_{2}$ emission rates from COSPEC data is similar. It is evident from equation (1) that the calculated emission rate will vary directly with wind speed. Thus, the effectiveness of any of the plume measurement methods described earlier depends on an accurate measurement of ambient wind speed in order to calculate an accurate emission rate. In addition, any uncertainty associated with the wind measurement will also be attached to the calculated emission rate.

\section{Discussion}

Wind measurements can be made from either the ground or the air. Wind speed is sometimes determined by using a hand-held anemometer for ground-based measurements. Airborne plume measurements typically utilize upper-air ("winds aloft") wind speeds measured by a variety of methods including wind vectors and speeds reported by local airports.

Alternatively, wind speed can be measured in situ by comparing true air speed, flying with and against the wind, and ground speed. Airborne wind measurements tend to be more reliable and accurate than ground-based measurements because wind speed can be determined near the elevation of the gas plume. On the ground or aloft, the wind should be measured on the upwind or lateral side of the volcano in order to be out of any turbulence created by the volcano or topography near the volcano. Extreme turbulence in the lee of a volcano can actually create winds flowing against the prevailing direction of travel (rotor effect).

During the past 30 years, many techniques have been used to calculate the wind data used for volcanic gas measurement calculations and emission rates. One of the earliest estimates of the error associated with wind speed determination was by Stoiber and others (1983) who suggested an error range of $\pm 10 \%$ to $\pm 20 \%$ with $\pm 40 \%$ being the worst case. Now, nearly two decades later, many investigators still believe this to be the typical range of error for wind speed measurements. For the earliest plume measurements made at Mount St Helens in 1980, estimated plume velocities were based on National Weather Service forecasts of winds aloft at appropriate plume altitudes (Harris and Others, 1981). Later, wind speeds were determined from differences in aircraft ground speed (obtained from FAA radar measurements) for flight paths parallel to the plume in both directions (Casadevall and others, 1981). Harris and others (1981) estimated that the wind speed was known only to about $\pm 25 \%$ for speeds between $5-10$ $\mathrm{ms}^{-1}$ with considerably higher uncertainty for lower wind speeds. Some investigators provide little or no statistical results for their wind determinations, while others provide no information on how plume velocity was measured (Kyle and others, 1990). Kyle and others (1994) 
reported wind speed errors of 5\% when using video to estimate plume speeds at Mt. Erebus volcano in Antarctic.

The ability to measure wind speed is based on both cost and location. At one end of the measurement spectrum is the ground based measurement site. This is probably the most common situation around the world. Ground-based wind data can come from a permanent weather station or from a hand-held anemometer. However, the hand-held method is probably the least representative of true plume velocity unless the plume being measured is next to the ground. It is the least expensive when the volcano is accessible by road. A hand-held anemometer near the analytical instrument can give a local surface-wind speed and can be repeated as many times as necessary during the gas measurement. As a result, it is possible to compute a statistical error for the measured wind-speed variation. The drawback to groundbased wind measurements is that they provide a minimum wind speed that does not necessarily reflect wind speeds at higher elevations where the plume resides. Elias and others (1998) reported that wind measured $3 \mathrm{~m}$ above the ground is 20 percent higher than that measured at a $1 \mathrm{~m}$ height. Ground-based measurements at the Montserrat Volcano Observatory showed 1.78x increase in wind speed with a change in position and elevation of ground measurement stations (Young and others, 1998). The station was moved from a hill top at about $1300 \mathrm{~m}$ elevation to another at about $1100 \mathrm{~m}$ and closer to being down wind from the vent area. The U.S. National Weather Service, based on World Meteorological Organization (1983) standards, requires that wind anemometers be placed $10 \mathrm{~m}$ above the ground surface in open terrain, and at a distance at least ten times the height of any nearby obstruction. Furthermore, the U.S. Environmental Protection Agency (1995) recommends that wind measurements for plume dispersal studies should be located as near as possible to the height of the plume. Thus, it appears that near surface wind measurements are only minimum values and are not particularly representative of plume speeds at higher elevations.

For upper air wind speed acquisition, the use of aircraft, tall towers, tethered and expendable radiosonde balloons, and ground-based profilers can be used with aircraft being the ultimate mobile observation station (Crescenti, 1994). Numerous airports located around the world send radiosonde balloons aloft every 12 hours to high altitudes. They report the wind speed at the elevation of most volcanic plumes. Problems arise if the distance from the launch site to the volcano is great. The reported precision for balloon wind speed measurements is 0.5 to $1 \mathrm{~ms}^{-1}$. The percent error for balloon-measured wind is variable, depending on the actual wind speed. The higher the wind, the lower the error. It is possible to obtain useful worldwide wind data from radiosonde balloons on a daily basis, usually at no cost, from the Internet (http://raob.fsl.noaa.gov/).

Aircraft based gas measurements are more expensive but allow the in situ measurement of prevailing winds. As mentioned earlier, wind measurements during airborne gas measurements at Mount St. Helens in the 1980's were obtained from ground radar tracking measurements or inertial navigation instrument (INS) measurements of the aircraft flying up and down the visible plume trajectory. The INS method times the aircraft travel over 10 nautical miles, both upwind and downwind, parallel to the plume direction. Averaging the difference gives a wind speed that can be used in emission rate calculations. No error bar can be placed on this type of wind speed measurement because there is only one measurement. Airborne flights in Central America by Casadevall and others (1984) report $10 \%$ accuracy in wind speed measurements using INS.

Typically, upwind and downwind measurements require a visible plume to follow or some other indication of wind direction. Due to lateral diffusion of the gas plume, flying along the edge of a plume (at plume height) may cause the operator to follow an oblique track away from 
the downwind direction. During measurements at quiescent volcanoes, plumes are seldom visible for use as a directional windsock. For volcanoes with visible plumes, it is possible to estimate plume velocity with rapid repeat ground-based photography of the plume (Hirabayashi and others, 1995, Kyle and others, 1994).

Besides the difficulties in making wind measurements, there is also the natural variation in wind speed at any given time. Turbulence and wind gusts create variations in direction and magnitude of the ambient wind. Reporting gas emission rates in tonnes per day assumes that the emission rate and wind remained somewhat constant throughout. The wind speed actually measured for these results are then assumed to be representative of the entire day. It is important then to make wind speed measurements as contemporaneous as possible to the gas measurement.

\section{New method for wind speed determinations}

\section{Continuous recording GPS measurements}

In situ wind vectors and wind speeds can now be calculated using GPS recorded aircraft flight paths. During USGS Cascades Volcano Observatory volcano gas measurement flights, an onboard data logger records GPS receiver position data (latitude and longitude) every two seconds. The GPS receiver is programmed to download two data sentences in the National Marine Electronics Association (NMEA) 0183 interface code, Sentence "GGA - GPS Fix Data and Sentence "VGT -Track made good and ground speed" (Rockwell, 1995). The parameters contained in these sentences are: time (UTC), latitude, longitude, signal quality, number of satellites tracked, antenna height above mean sea level, geoidal separation, differential reference, ground track direction of travel (true), ground track direction of travel (magnetic), and speed in both knots and kilometers per hour (Rockwell, 1995). The 2s interval of GPS data collection is then interpolated during post processing to produce a $1 \mathrm{~s}$ interval in order to register with the $1 \mathrm{~s}$ data from chemical and other sensors.

\section{Neutral Wind Circles}

When making airborne volcanic gas measurements at a remote volcano with no visible plume, an estimate of the ambient wind speed and even wind direction is often unknown. Under such conditions, the pilot should be directed to fly a series (3-4) of neutral circles. This involves maintaining a constant altitude and turn radius using no throttle control or automatic pilot and should be done adjacent or upwind of the volcano, but not in the lee of the volcano, and at the expected altitude of the plume. Figure 1 shows the GPS track of such a series of 1.5$\mathrm{km}$ diameter neutral wind circles. In the case shown, the pilot is not changing altitude, turn radius, or throttle speed, and the succession of circles, each about two minutes in duration, illustrates how the aircraft is slowly pushed downwind (to the NNE) by the prevailing winds. During data reduction, this provides an accurate indication of wind direction and, thus, the likely location of any plume exiting the volcano. During flight, the GPS receiver can be observed, heading and ground speed recorded, giving information on likely plume location. Once the chemical measurements of the plume are completed, a second series of neutral wind circles should be flown if the core of the plume is found to be distinctly different from the altitude of the initial wind circles or that the wind speed and direction have changed.

Since all of the GPS data is recorded in a data logger, it can be downloaded into a spreadsheet after the flight for later detailed analysis. 


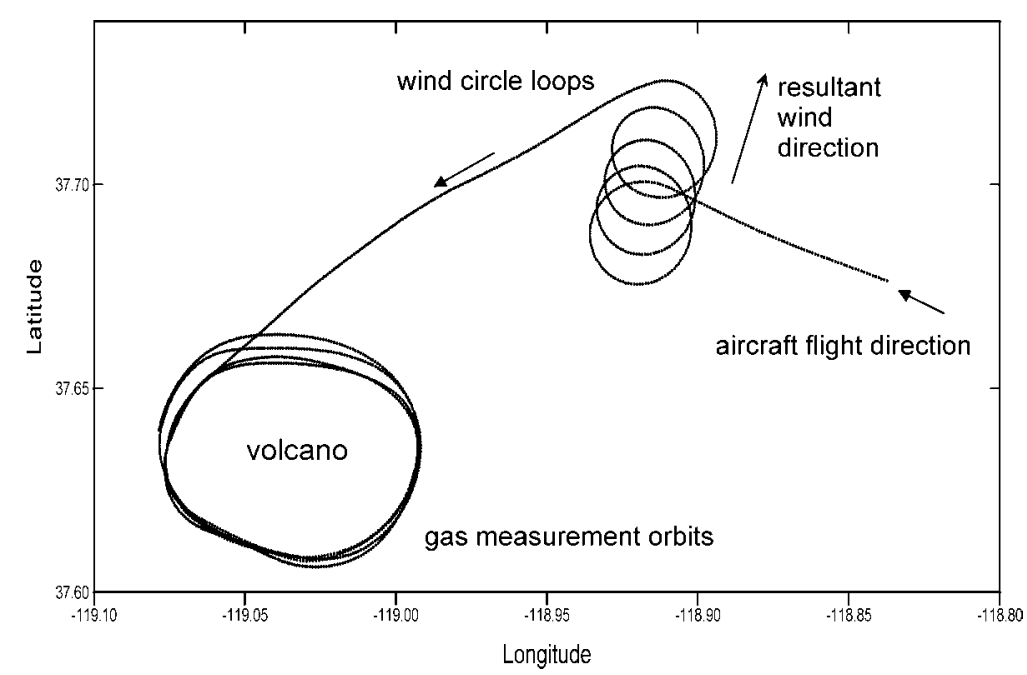

Figure 1. Plot of GPS determined aircraft positions during neutral wind circle wind speed determination and gas measurement orbits. Prevailing winds push aircraft downwind, shown here by change of position of wind loops towards the NNE.

The peak values (maximum aircraft speeds) are recorded when the aircraft has a maximum tailwind push from the wind and are shown by the solid squares in figure 2. Likewise, minimum aircraft ground speeds are recorded when the aircraft is flying directly into the wind and are shown by the solid circles in figure 2 .

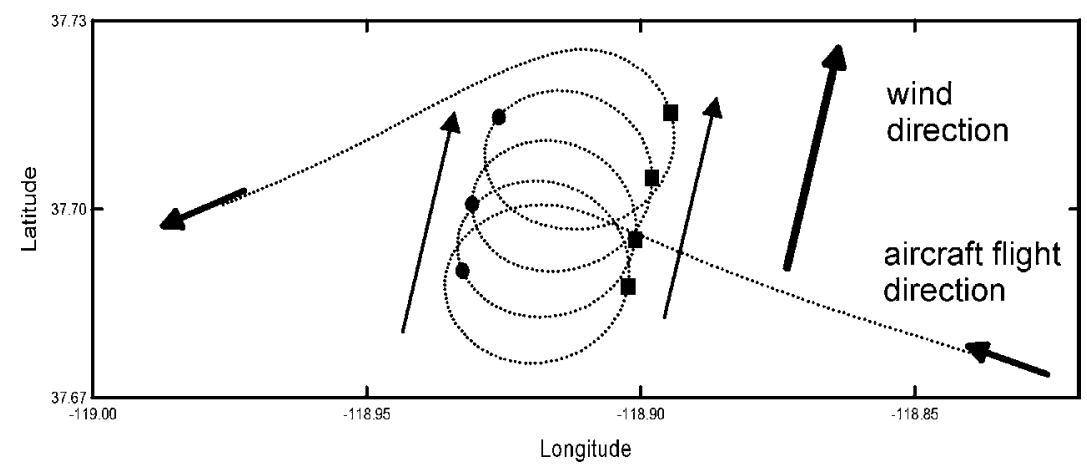

Figure 2. Plot of GPS determined aircraft positions during neutral wind circle wind direction determination as illustrated in figure 1. Development of wind vectors from maximum and minimum GPS ground speeds. Maximum tailwinds are shown by squares, maximum headwinds are shown by filled circles. See figure 3 for magnitudes.

Figure 3 shows a plot of aircraft ground speeds from recorded GPS data for the series of neutral wind circles in figure 1 and 2. To calculate wind speed, average a 3-s interval of data around each headwind maximum and tailwind minimum and subtract the headwind average from the tailwind average and divide by 2 . This procedure is illustrated in table 1 . 
Table 1

Calculation of wind speed

\begin{tabular}{|c|c|c|c|c|c|}
\hline wind data & & $\begin{array}{l}\text { tailwind } \\
\text { average } \\
\mathrm{ms}^{-1}\end{array}$ & $\begin{array}{c}\text { headwind } \\
\text { average } \\
\mathrm{ms}^{-1}\end{array}$ & $\begin{array}{c}\text { windspeed }^{1} \\
\mathrm{~ms}^{-1}\end{array}$ & $\begin{array}{c}\text { average } \\
\text { windspeed } \\
\mathrm{ms}^{-1} \\
\end{array}$ \\
\hline $\begin{array}{r}\text { Figure } 3 \\
\text { orbit } 1 \\
\text { orbit } 2 \\
\text { orbit } 3 \\
\text { orbit } 4\end{array}$ & Mammoth Mtn, $\mathrm{CA}^{2}$ & $\begin{array}{l}88.5 \\
88.6 \\
88.7 \\
89.3\end{array}$ & $\begin{array}{l}74.5 \\
74.1 \\
76.0 \\
77.3\end{array}$ & $\begin{array}{l}7.0 \\
7.3 \\
6.9 \\
6.0\end{array}$ & 6.8 \\
\hline $\begin{array}{l}\text { Figure } 5 \\
\text { orbit } 1 \\
\text { orbit } 2 \\
\text { orbit } 3,5 \mathrm{~km}\end{array}$ & Augustine Volcano, $\mathrm{AK}^{3}$ & $\begin{array}{l}88.1 \\
89.5 \\
89.3\end{array}$ & $\begin{array}{l}69.6 \\
72.0 \\
71.8\end{array}$ & $\begin{array}{l}9.3 \\
8.7 \\
8.7\end{array}$ & 8.9 \\
\hline $\begin{array}{l}\text { Figure } 7 \\
\text { Traverse } 1 \\
34 \text { pairs }\end{array}$ & Pu`u `O`o vent , $\mathrm{HI}^{4}$ & 76.2 & 57.6 & & $\begin{array}{c}9.3 \\
9.6^{4}\end{array}$ \\
\hline
\end{tabular}

${ }^{1}$ (tailwind - headwind)/2

${ }^{2} 4$ tailwinds, 4 headwinds

${ }^{3} 2$ tailwinds, 2 headwinds

4 average of 34 tailwind - headwind pairs

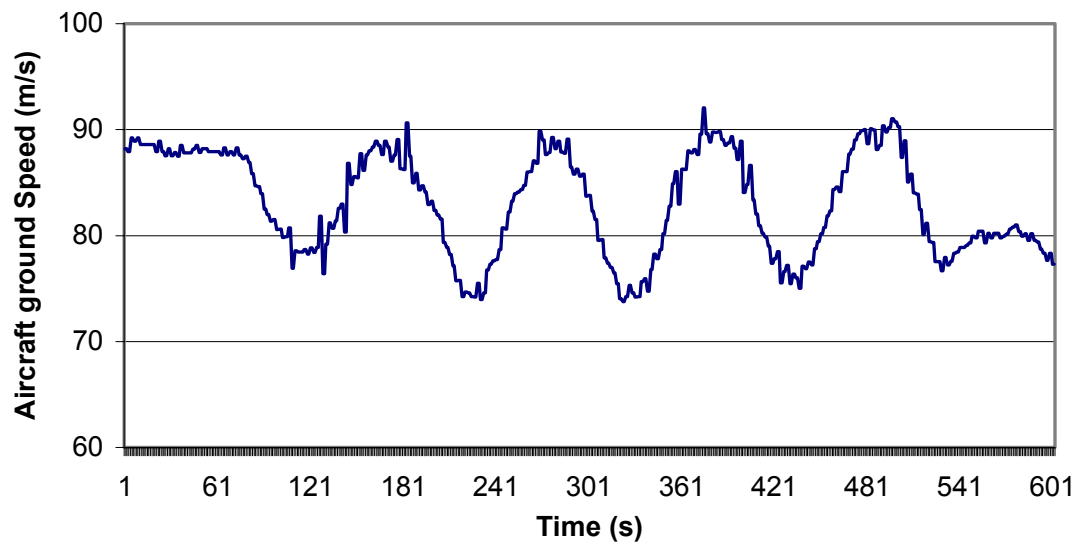

Figure 3. Plot of GPS aircraft ground speed (meters per second) during the series of neutral wind circles illustrated in figure 1. Peak values of aircraft ground speed indicate maximum tailwind push by wind. Minimum values of aircraft speed indicate maximum headwind.

To test whether calculated wind speeds are sensitive to the diameter of the wind circles, two circles of $2-\mathrm{km}$ diameter and one of 5-km diameter were flown in succession (fig. 4). The headwind and tailwind ground speeds are not measurably different (fig. 5) for the different circles, suggesting that the diameter of the wind circles is unimportant. 


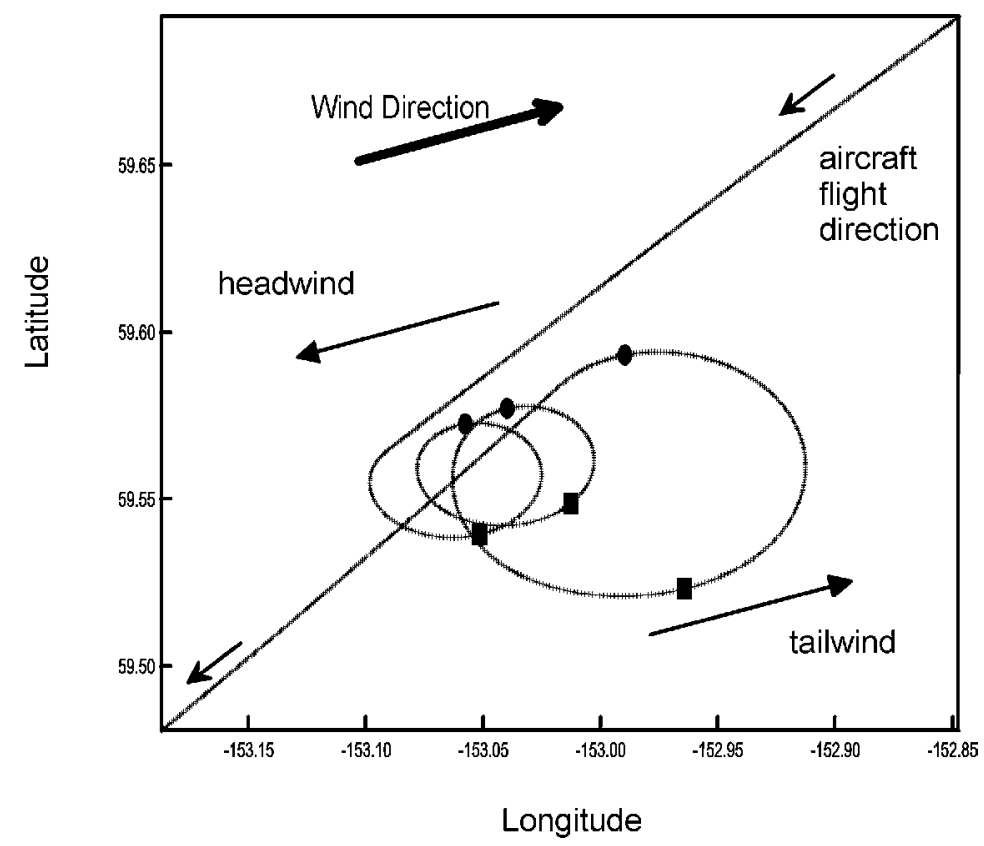

Figure 4. Plot of GPS determined aircraft positions during neutral wind circle size test. Prevailing winds push aircraft to the east northeast (downwind). Tailwind maxima are shown as squares and headwind maxima are shown as filled circles. The small wind loops have a diameter of approximately $2 \mathrm{~km}$ and the large loop diameter is approximately $5 \mathrm{~km}$.

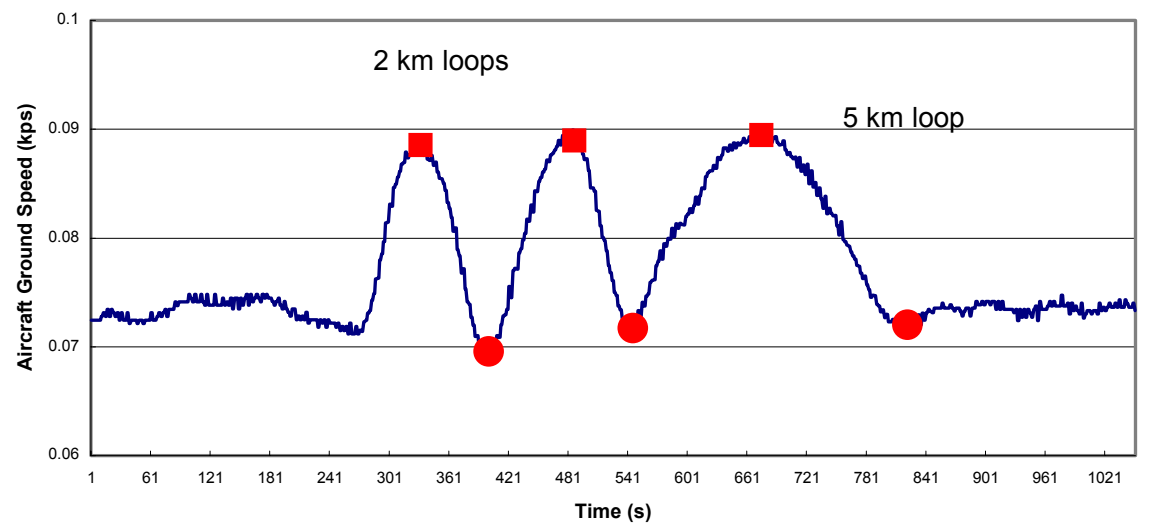

Figure 5. Plot of GPS aircraft ground speed $\left(\mathrm{ks}^{-1}\right)$ during wind circle and size test shown in figure 4. Aircraft ground speed maxima (squares) occur with maximum tailwind push by ambient winds and minima (filled circles) occur with maximum headwind push. Note that the diameter of the wind circles has little effect on the wind speed determination. Wind speeds determined from large wind circles may be slightly more statistically valid because more data can be collected during the periods of maximum and minimum aircraft ground speed. 


\section{Visible Plume Method}

The visible plume method is similar to the airspeed and radar-tracking method used for the Mount St Helens plume measurements in the 1980's; except that all the data are recorded onboard in the data logger for later analysis and no external assistance from the FAA is required. The aircraft is flown on a downwind leg (tailwind direction) near the emitted and visible plume. An example of this method is shown in figure 6. After one minute of flight, the aircraft is turned around and flown on an upwind leg (headwind direction) for one minute of flight. The data are then displayed on a spreadsheet chart for analysis. Figure 7 shows a plot of GPS recorded aircraft speeds collected while utilizing this method at Kilauea volcano in Hawaii. Averaging the ground speeds for each track, then subtracting one from the other and dividing by two, results in a wind speed of $9.3 \mathrm{~ms}^{-1}$ (table 1).

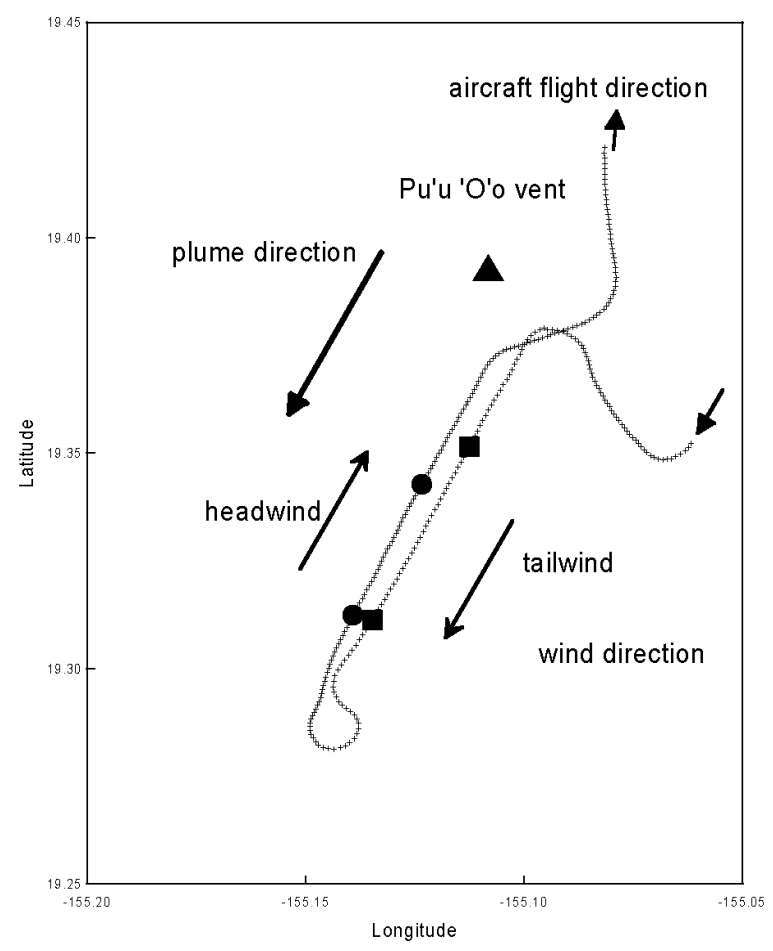

Figure 6. GPS determined positions of aircraft paralleling the visible downwind plume near Pu 'u 'O'o vent, Kilauea volcano, Hawaii. Tailwind track direction lies between squares, headwind track direction lies between circles, Pu 'u 'O'o vent is represented by large triangle. 


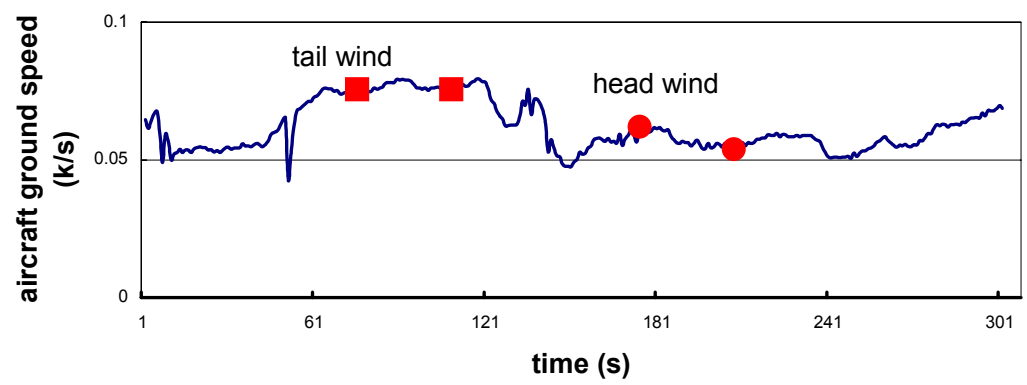

Figure 7. Plot of GPS aircraft ground speed $\left(\mathrm{ks}^{-1}\right)$ versus elapsed time while paralleling the plume, downwind near Pu'u 'O'o vent Hawaii. Tailwind values between squares and headwinds between filled circles from locations in figure 6. Values are averaged, the difference then halved to compute one aircraft ground speed [(tailwind-headwind)/2 = wind speed]. To compute multi-wind speeds, each headwind is subtracted from each tailwind, then each difference divided by 2 resulting in 34 wind speed calculations (table 1).

\section{Wind calculation error}

To fully report gas emission rates and their precision in published reports, wind speed measurement error must be reported. Not quantifying the wind speed data in reports can lead readers to assume a wind error for the data. For the examples shown in figures 1-3, the largest four measurements from each of the tailwind positions (three averaged ground speeds) and the smallest four measurements headwind positions (three averaged ground speeds) for each orbit were used to calculate wind speeds. The data from figure 3 resulted in an average wind speed of $6.8 \mathrm{~ms}^{-1} \pm 0.5 \mathrm{~ms}^{-1}$. This is an error of $7.0 \%$. Calculating wind speeds from the example shown in figure 5 produces in an average $8.9 \pm 0.28 \mathrm{~ms}^{-1}$. The corresponding error is $3 \%$. Calculating the wind speed for the visible plume method illustrated in figure 7 produces a wind speed of $9.3 \mathrm{~ms}^{-1}$ with no error attached as there is only one wind speed calculated. If each of 34 pairs of wind speed is used from figure 7, the corresponding wind speed is $9.6 \mathrm{~ms}^{-1}$ with a corresponding error of $1.7 \mathrm{~ms}^{-1}$. The precision for these results (table 2) are all comparable or better than the errors for wind speed reported by Stoiber (1983, \pm 10 to $\pm 20 \%$ ). It can be seen that multiple wind speeds need to be measured to determine wind speed error and precision during airborne gas measurements.

Plotting the maximum and minimum wind speeds of a wind circle chart can also be used to determine a wind direction vector (fig. 2). The vector direction can then be used in the calculation of wind path corrections for curved or oblique plume traverses (Gerlach and others, 1999). 
Table 2

Calculated standard deviation and percent error for wind measurements

\begin{tabular}{llccc}
\hline wind data & $\begin{array}{l}\text { location of } \\
\text { wind data }\end{array}$ & $\begin{array}{c}\text { average } \\
\text { wind } \\
\mathrm{ms}^{-1}\end{array}$ & $\begin{array}{c}\text { standard } \\
\text { deviation } \\
\mathrm{ms}^{-1}\end{array}$ & $\begin{array}{c}\% \\
\text { error }\end{array}$ \\
\hline Figure 3 winds & Mammoth Mountain, CA & 6.8 & 0.5 & $7.0 \%$ \\
Figure 5 winds & Augustine Volcano, AK & 8.9 & 0.3 & $3.1 \%$ \\
Figure 7 winds & Pu'u'O'O vent, HI & 9.3 & none & none \\
Figure 7 winds & Pu'u'O'O vent, HI & 9.6 & 1.6 & $16.7 \%$ \\
\hline
\end{tabular}

\section{SUMMARY}

A variety of instruments and techniques are used to study and measure the gases in volcanic plumes. Regardless of the approach an accurate measure of plume velocity must be made. Wind measurements made near the elevation of the plume are considerably more representative of plume velocity than ground-based measurements. The airborne wind measurement technique described here utilizing neutral wind circles are made in the same wind regime and at the same elevation as the plume. This approach does not depend on the presence of a visible plume. The measurements can also be made close in time to when the chemical measurements of the plume are made in order to reduce the likelihood of changes in the wind conditions between the plume and wind measurements. Finally, the wind circle method provides an opportunity to statistically evaluate the wind data and compute an uncertainty. The other "parallel to the plume" wind measurement technique described here is applicable to volcanoes with either a visible plume or where the wind direction is obvious. Flying upwind and downwind adjacent to a visible plume has many of the same advantages as the neutral circle method except that the precision of the wind speed is unknown. 


\section{References}

Casadevall, T.J., Johnston, D.A., Harris, D.M., Rose, W.I., Malinconico, L.L., Stoiber, R.E., Bornhorst, T.J., Williams, S.N., Woodruff, Laurel, and Thompson, J.M., 1981, $\mathrm{SO}_{2}$ emission rates at Mount St. Helens from March 29 through December, 1980, in Lipman, P.W. and Mullineaux, D.L., eds., The 1980 eruptions of Mount St. Helens, Washington: U.S. Geological Survey Professional Paper 1250, p. 193-200.

Casadevall, T.J., Rose, W.I., Fuller, W.H., Hunt, W.H., Hart, M.A., Moyers, J.L., Woods, D.C., Chuan, R.L., and Friend, J.P., 1984, Sulfur dioxide and particles in quiescent volcanic plumes from Poas, Arenal, and Colima volcanoes, Costa Rica and Mexico: Journal of Geophysical Research, v. 89, no. D6, p. 9633-9641.

Cresenti, H.G., 1994, Overview of PAMS Meteorological Monitoring requirements, in Proceeding of the EPA/AWMA Symposium on measurement of toxic and related air pollutants, Air \& Waste Management Association, Durham NC, p. 245-253.

Elias, T., Sutton, A.J., Stokes, J.B., and Casadevall, T.J., 1998, Sulfur dioxide emission rates of Kilauea Volcano, Hawaii, 1979-1997, USGS, Open-File Report 98-462.

Francis, P., Burton, M.R., and Oppenheimer, C., 1998, Remote measurements of volcanic gas compositions by solar occultation spectroscopy: Nature, v. 396, p. 567-570.

Gerlach, T.M., Delgado, H., McGee, K.A., Doukas, M.P., Venegas, J.J., and Cárdenas, L., 1997, Application of the LI-COR $\mathrm{CO}_{2}$ analyzer to volcanic plumes: A case study, Volcán Popocatéptl, Mexico, June 7 and 10, 1995: Journal of Geophysical Research, v. 102, no. B4, p. 8005-8019.

Gerlach, T.M., Doukas, M.P., McGee, K.A., and Kessler, Richard, 1999, Airborne detection of diffuse carbon dioxide emissions at Mammoth Mountain, California: Geophysical Research Letters, v. 26, n. 24, p. 3661-3664.

Harris, D.M., Sato, M., Casadevall, T.J., Rose, W.I., and Bornhorst, T.J., 1981, Emission rates of CO2 From plume measurements, in, Lipman, P.W., and Mullineaux, D.L., eds., The 1980 eruptions of Mount St. Helens, Washington, U.S. Geological Survey Professional Paper 1250, p. 201-207.

Hirabayashi, J., Ohba, T., and Nogami, K., Discharge rate of SO2 from Unzen volcano, Japan, (1995) Geophysical Research Letters, v.22, n. 13, pp 1709-1712.

Horrocks, L., Burton, M., Francis, P., and Oppenheimer, C., 1999, Stable gas plume composition measured by OP-FTIR spectroscopy at Masaya Volcano, Nicaragua, 1998-1999: Geophysical Research Letters, v. 26, p. 3497-3500.

Kyle, P.R., Meeker, K., and Finnegan, D., 1990, Emission rates of sulfur dioxide, trace gases and metals from Mount Erebus, Antarctica: Geophysical Research Letters, v. 17, p. 2125-2128. 
Kyle, P.R., Sybeldon, L.M., McIntosh, W.C., Meeker, K., and Symonds, R., 1994, Sulfur dioxide emission rates from Mount Erebus, Antarctica, in Kyle, P.R., ed., Volcanological and Environmental Studies of Mount Erebus, Antarctica, Volume 66: Washington, D.C., American Geophysical Union, p. 69-82.

Love, S.P., Goff, F., Counce, D., Siebe, C., and Delgado, H., 1998, Passive infrared spectroscopy of the eruption plume at Popocatéptl volcano, Mexico: Nature, v. 396, p. 562-567.

McGee, K.A., 1992, the structure, dynamics, and chemical composition of noneruptive plumes from Mount St. Helens, 1980-88: Journal of Volcanology and Geothermal Research, v. 51, p. 269-282.

McGee, K.A., Doukas, M.P., and Gerlach, T.M., 2001, Quiescent hydrogen sulfide and carbon dioxide degassing from Mount Baker, Washington: Geophysical Research Letters, v. 28, no. 23, p. 4479-4483.

Millán, M.M. and Hoff, R.M., 1978, Remote sensing of air pollutants by correlation spectroscopy-Instrumental response characteristics: Atmospheric Environment, v. 12, p. 853864.

Rockwell International, Precision Lightweight GPS receiver (PLGR), Interface control document, NMEA 0183, 1995, Rockwell International, Collins Avionics \& Communications Division, Cedar Rapids, Iowa.

Stoiber, R.E., Malinconico, L.L., and Williams, S.N., 1983, Use of the correlation spectrometer at volcanoes, in Tazieff, Haroun and Sabroux, J.C., eds., Forecasting Volcanic Events:

Amsterdam, Elsevier, p. 425-444.

U.S. Environmental Protection Agency, 1995, Quality assurance handbook for air pollution measurement systems, Volume IV, Meteorological measurements, EPA/600/R-94/038d, Office of research and development, Washington D.C.

World Meteorological Organization (1983): Guide to Meteorological Instruments and Methods of Observation (fifth edition), WMO no. 8; Geneva Switzerland

Young, S.R., Francis, P.W., Barclay, J., Casadevall, T.J., Gardner, C.A., Darroux, B., Davies, M.A., Delmelle, P., Norton, G.E., Maciejewski, A.J.H., Oppenheimer, C.M.M., Stix, J., and Watson, I.M., 1998, Monitoring SO2 emission at Soufriere Hills volcano: Implications for change in eruptive conditions: Geophysical Research Letters, v. 25, p. 3681-3684. 